\title{
Relative Contribution of Upper and Lower Lumbar Spinal Segments to Flexion/Extension: Comparison between Normal Spines and Spines with Disc Disease in Asian Patients
}

\author{
Tarun Bali, Malhar N. Kumar \\ Department of Orthopedics, Hosmat Hospital, Bangalore, India
}

\begin{abstract}
Study Design: Prospective cohort study.
Purpose: To evaluate the contribution of upper and lower lumbar segments to flexion and extension of the lumbar spine in normal and diseased spines.

Overview of Literature: The specific contributions of upper and lower lumbar segments during flexion/extension have rarely been reported. Furthermore, no comparisons between the flexion/extension behaviors of normal and diseased spines have been reported until now.

Methods: Flexion and extension lateral radiographs of 52 adult, asymptomatic volunteers, and 67 adult patients with lumbar spine disc disease were measured using software for total lumbar lordosis, upper lumbar lordosis and lower lumbar lordosis and the intervertebral angles of all segments.

Results: In asymptomatic volunteers, the range of movement between flexion and extension was a mean of only $4.2^{\circ}$ in the lower lumbar spine and a mean of $19.4^{\circ}$ in the upper lumbar spine. In patients with disc degeneration, the range of movement between flexion and extension was an average $6.5^{\circ}$ for lower lumbar spine and $15.6^{\circ}$ for the upper lumbar spine.

Conclusions: The results showed that upper lumbar spine contributes more to the range of motion in flexion and extension than the lower lumbar spine in asymptomatic individuals without lumbar disc disease, as well as in patients with disc degeneration.
\end{abstract}

Keywords: Lordosis; Lumbar vertebrae; Lumbosacral region; Intervertebral disc degeneration; Intervertebral disc disease

\section{Introduction}

Numerous parameters have been investigated for their possible etiological role in adjacent segment degeneration (ASD). They include age and gender of the patients, preexisting adjacent level degenerative changes, number of segments included in the fusion, level of physical activity following spinal fusion, sagittal profile alteration following fusion, and nature of the index surgical procedure (posterolateral fusion vs. posterior lumbar inter body fusion, and addition of decompressive laminectomy/facetectomy along with fusion) [1-5]. Controversy exists in earlier literature regarding hypermobility at the adjacent segment following spinal fusion. Hypermobility of the

Received Jan 12, 2015; Revised Feb 5, 2015; Accepted Feb 25, 2015

Corresponding author: Tarun Bali

Department of Orthopedics, Hosmat Hospital, No. 45, Magarath Road, Off Richmond Road, Bengaluru, Karnataka 560025, India

Tel: +91-80-4128-9242, Fax: +91-80-2559-3747, E-mail: drtarunbali8@gmail.com 
adjacent segment is a cause of ASD according to certain studies; but others have reported that hypermobility does not occur following spinal fusion. Background on the relative contributions of the upper and lumbar spines is essential to confirm that hypermobility of the upper lumbar spine occurs when the lower lumbar segments have been fused. Parkinson et al. [6] emphasized the need to study the lumbar spine movements in terms of upper and lower segments. They found statistically significant differences in the contribution of upper and lower lumbar segments during sitting versus standing tasks and also noted significant gender-based differences in the segmental motion.

The aim of this prospective study was to measure the range of motion in the upper and lower spinal segments in the normal population and in patients with degenerative disc disease of the lumbar spine. We studied the upper and lower segment movements separately since the lower lumbar segments (L4-5 and L5-S1) are most often involved in disc degeneration and spondylolisthesis and are also most subject to arthrodesis in these disorders. Even in asymptomatic volunteers, the upper and lower lumbar spine segments were measured separately since the coupling and translation movements are different in the upper (L1-2, L2-3, and L3-4) and the lower lumbar (L4-5 and L5-S1) segments [7].

\section{Materials and Methods}

Measurements were made on standing, flexion, and extension lateral radiographs of 52 adult volunteers. Digital radiographs were obtained and measurements were performed using software (DICOM, Kriens, Switzerland). Volunteers were selected on the basis of the following criteria, i.e., ages between 20 years and 50 years, absence of history of spinal disease or operation in the past, normal clinical spinal examination, normal radiographic appearance of the spine, absence of lumbosacral segmentation anomalies, absence of abnormalities in the hips, knees and ankles, and absence of limb length inequality. Informed written consent was obtained from the participants. The Institutional Review Board of HOSMAT Hospital approved the study. There were 29 males and 23 females. The mean age of the participants was 36 years (range, 20-60 years).

The prospective study was performed on 67 adult patients with degenerative lower lumbar disc disease seen in HOSMAT Hospital between February 2008 and July 2011.
There were 42 male and 25 female patients. The mean age of the patients was 44.2 years (range, 19-72 years). Skeletally mature adult patients with degenerative lower lumbar disc (L4-5 and/or L5-S1 segments) disease were included in the study. The diagnoses included degenerative disc disease with spondylolisthesis, disc degeneration with axial low back pain/sciatica, and spinal canal stenosis with neurogenic claudication. Patients with spinal infections, vertebral fractures, and disc degeneration involving the upper lumbar segments (L1-2 to L3-4 discs), lumbosacral segmentation anomalies and tumors were excluded from the study. There were 38 males and 29 females.

Anteroposterior and lateral radiographs (standing erect, flexion and extension views) were obtained in all patients. For flexion/extension views, we employed the technique described by Morvan et al. [8]. For the extension view, the subject was made to stand erect and extend backwards as much as possible, keeping the arms raised behind the head. The buttocks were supported by a wedge placed posteriorly. For the flexion view, the subject was seated on a stool with a wedge below the thighs to raise the knees. The spine was flexed forward with the arms hanging downwards. For the lateral view, the subject was made to stand erect looking straight ahead with knees in extension. Hands were made to rest on a vertical support with the elbows flexed partially.

In each radiograph, the following parameters were measured, i.e., global lumbar lordosis (between superior end plate of L1 and S1), lordosis of upper lumbar spine (between the superior end plate of L1 and L4 vertebra), and lordosis of lower lumbar spine (superior end plate of L4 and S1). Intervertebral angles were measured at each of the five lumbar disc spaces to confirm the changes in the disc spaces in the upper and lower lumbar segments (Figs. 1, 2). Intervertebral angles were defined as the angle between the vertebral end plates on either sides of the intervertebral disc. In patients with lumbar disc disease, types of degenerative changes were recorded as narrowing of disc space, sclerosis of vertebral end plates, spondylophytes and narrowing of intervertebral foramina. Disc space height was measured according to the method described by Pope et al. [9]. Degenerative changes were classified into four grades (grade 0 to 3 ) according to the criteria of Wilke et al. [10]. Twenty-six patients had grade 1 (degenerative changes); 22 patients had grade 2 (degeneration), and 19 patients had grade 3 (degenerative changes). Measurements were made by three independent 

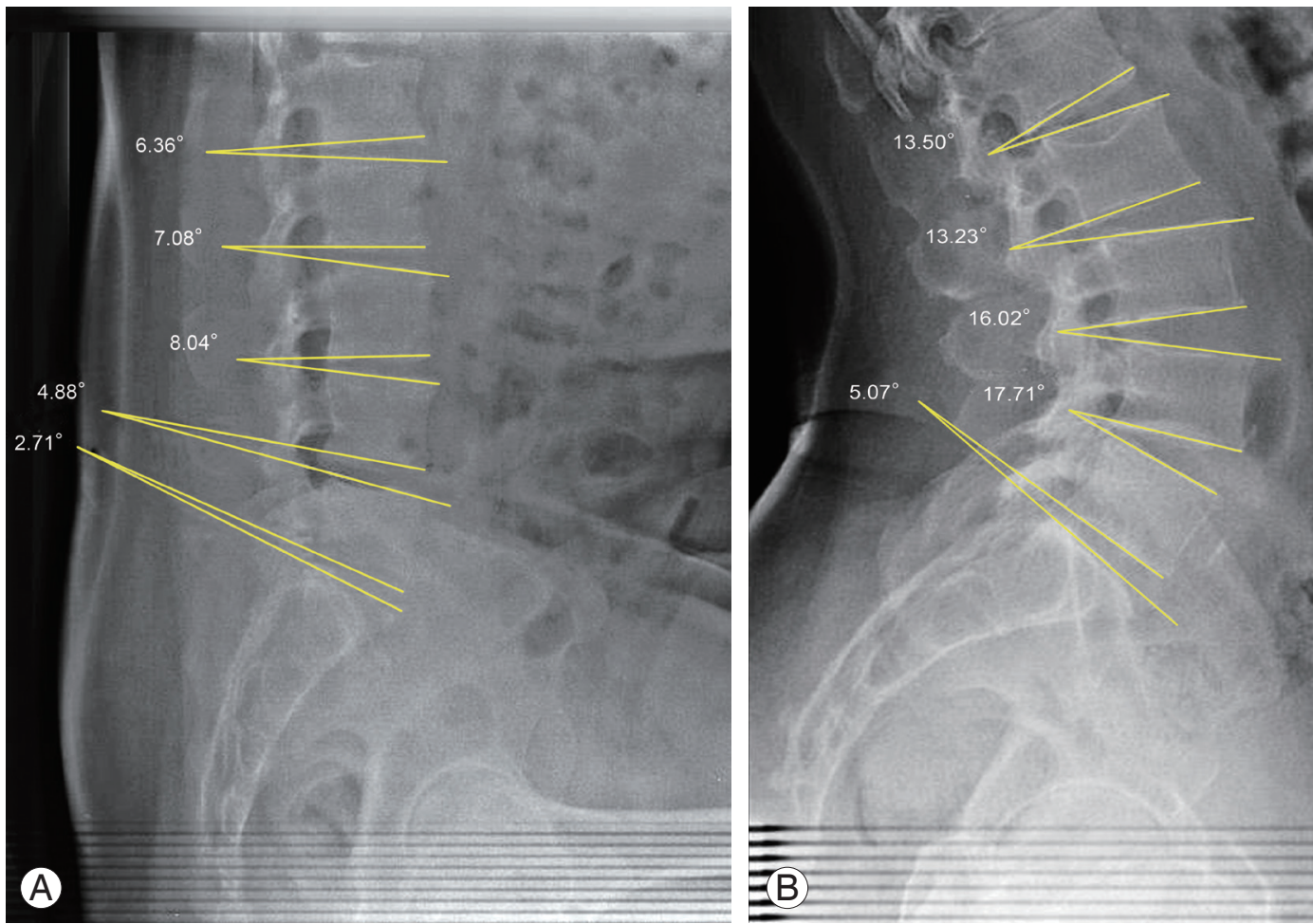

Fig. 1. (A) Flexion and (B) extension lateral lumbar radiographs of asymptomatic volunteer showing intervertebral angles.
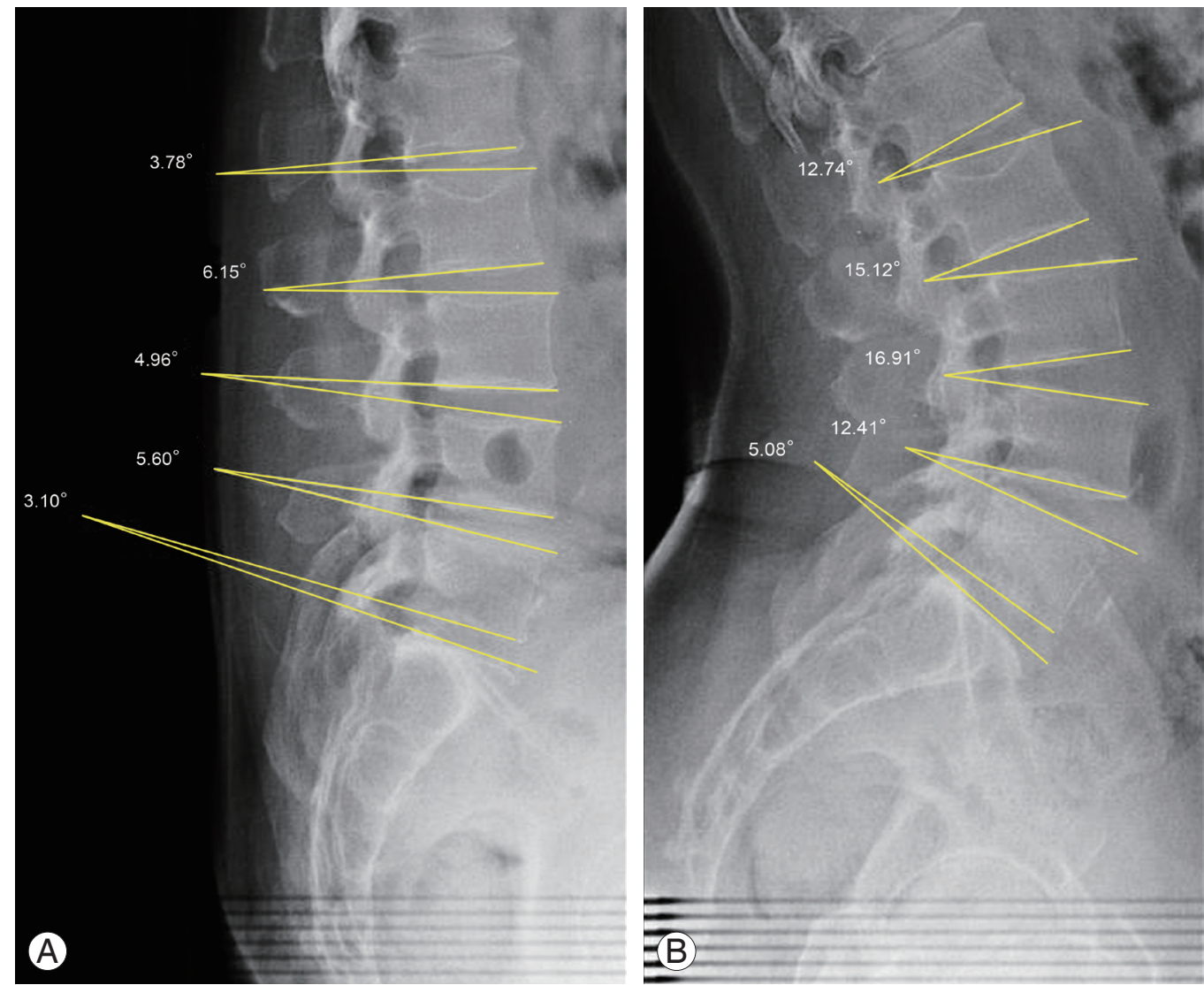

Fig. 2. (A) Flexion and (B) extension lateral lumbar radiographs of patient with lumbar disc degeneration showing intervertebral angles. 
Table 1. Mean range of motion (ROM) in upper and lumbar spine segments

\begin{tabular}{|c|c|c|c|c|c|c|}
\hline & \multicolumn{3}{|c|}{$\begin{array}{l}\text { Asymptomatic volunteers } \\
\text { (mean ROM in degrees) }\end{array}$} & \multicolumn{3}{|c|}{$\begin{array}{l}\text { Patients with lumbar disc disease } \\
\text { (mean ROM in degrees) }\end{array}$} \\
\hline & Flexion & Extension & ROM & Flexion & Extension & ROM \\
\hline Upper lumbar spine & 17.5 & 38.9 & 21.4 & 13.5 & 29.1 & 15.6 \\
\hline Lower lumbar spine & 28.6 & 37.8 & 9.2 & 8.5 & 15 & 6.5 \\
\hline
\end{tabular}

observers and the average of the three values was taken for each observation.

Statistical analyses of the data were performed using the SPSS ver. 17.0 (SPSS Inc., Chicago, IL, USA). We analyzed the lordosis at lower lumbar spine (L4-5 and L5-S1 discs) and upper lumbar discs (L3-4, L2-3, and L1-2). Student $t$-test was used to test the significance of difference between quantitative variables. A $p$-value $<0.05$ was taken to denote significant relationship.

\section{Results}

Among the asymptomatic normal volunteers, the mean total lumbar lordosis in the neutral standing lateral radiograph was $55.1^{\circ}\left(\right.$ range, $\left.39^{\circ}-62^{\circ}\right)$. The mean lower lumbar lordosis was $30.4^{\circ}$ (range, $22^{\circ}-40^{\circ}$ ) and the mean upper lumbar lordosis was $24.7^{\circ}$ (range, $10^{\circ}-32^{\circ}$ ). The mean lower lumbar lordosis during flexion was $28.6^{\circ}$ and $32.8^{\circ}$ during extension. The mean upper lumbar lordosis during flexion was $17.5^{\circ}$ and $36.9^{\circ}$ during extension. Thus the range of movement between flexion and extension was a mean of only $4.2^{\circ}$ (range, $0^{\circ}-14^{\circ}$ ) in the lower lumbar spine and a mean of $19.4^{\circ}$ (range, $9^{\circ}-44^{\circ}$ ) in the upper lumbar spine (Table 1).

In patients with lumbar disc disease, the mean value for lower lumbar lordosis in flexion was $8.5^{\circ}$ (range, $3.1^{\circ}$ $4.9^{\circ}$ ) and the mean value in extension was $15^{\circ}$ (range, $7.6^{\circ}-28.3^{\circ}$ ). The mean value for upper lumbar lordosis in flexion was $13.5^{\circ}$ (range, $7.7^{\circ}-26.5^{\circ}$ ) and the mean value in extension was $29.1^{\circ}$ (range, $18.4^{\circ}-45.7^{\circ}$ ). The range of movement between flexion and extension was an average $6.5^{\circ}$ for lower lumbar spine (range, $1.4^{\circ}-12.9^{\circ}$ ) and $15.6^{\circ}$ for the upper lumbar spine (range, $6.9^{\circ}-28.2^{\circ}$ ).

There was a statistically significant difference between the range of motion in the upper lumbar spine and lower lumbar spine in asymptomatic volunteers $(p=0.002)$ and in patients with lumbar disc disease $(p=0.001)$. The range of motion was higher in the upper lumbar spine, as com- pared with the lower lumbar spine in asymptomatic volunteers, as well as in patients with disc degeneration. The global range of motion was less in patients with lumbar disc disease, but the upper lumbar spine contributed more to the range of motion in this group as well.

There was a statistically significant difference between the ranges of motion in the upper lumbar spine in asymptomatic volunteers and in patients with disc degeneration $(p=0.03)$. The difference in the range of motion in the lower lumbar spine between asymptomatic volunteers and in patients with disc degeneration was also significant $(p=0.004)$.

\section{Discussion}

Clinical manifestations of ASD may take the form of spondylolisthesis, kyphosis, retrolisthesis, spinal canal stenosis, stress fracture, or scoliosis. Ahn et al. [11] showed in their series that reoperation was required to address ASD in $3.5 \%$ of patients within a decade of index operation. Whether symptomatic or not, radiographic adjacent segment changes occur more frequently in patients with fusion procedures than in patients who had no surgical intervention for lumbar disc disease [11].

Contradictory conclusions exist on the occurrence of hypermobility in the cranial adjacent lumbar disc following segmental spinal fusion. Some studies reported hypermobility of the adjacent segments in the followup period. Abnormal sagittal profile causes compensatory hypermobility in the adjacent discs in an effort to balance the deformity [12-14]. Lee et al. [15] attributed ASD to altered sagittal rotation of the adjacent vertebrae following spinal fusion. They observed a $37 \%$ of global increase in the sagittal rotation of the adjacent vertebrae following fusion. However, according to Chou et al. [16], relative hypermobility of the adjacent segment is a more probable cause of ASD than global increase in mobility of the adjacent spinal segment. Axelsson et al. [17] used 
radiostereometric analysis to measure translation of adjacent vertebrae before and 5 years after spinal fusion. They found no increase in the mobility of the adjacent segment and opined that biomechanical effects of fusion on the adjacent segment have been overestimated in earlier studies. Kettler et al. [18] and Mimura et al. [19] studied the effect of disc degeneration on the segmental motion of the lumbar spine in cadaveric spine specimens,. They found no evidence of increased segmental motion (instability) in association with disc degeneration during flexion/extension and lateral bending movements. While Kettler et al. [18] noted some instability only in axial rotation, Mimura et al. [19] observed a decreased range of motion during flexion/extension and lateral bending.

Prior to drawing any conclusions regarding hypermobility, it is necessary to understand the segmental motion behavior of the lumbar spine during flexion and extension in normal, as well as diseased lumbar spines. An earlier clinical study using the 'flexicurve' technique studied the upper and lower lumbar spinal range of motion separately and found no predictable pattern of increase in upper lumbar range of motion in the presence of lower lumbar spinal pathology [20]. A wide variation in the upper to lower lumbar spine range of motion was found in normal persons, as well as in diseased states. The present study indicated that the upper lumbar spine contributed more to the range of motion in flexion and extension than the lower lumbar spine. This finding occurred in asymptomatic volunteers as well as patients with lumbar disc disease, similar to the observations of Li et al. [21] that upper lumbar vertebrae have higher range of flexion during flexion-extension movements. The global range of motion was less in patients with disc degeneration, as compared with asymptomatic volunteers, but the upper lumbar spine contributed more to movement even in these patients.

\section{Conclusions}

The results of the present study suggested that there is a decrease in the range of movement of the entire lumbar spine, as well as in the upper and lower lumbar spines, in symptomatic degenerative disc diseases, as compared with the mean ranges of motion in lumbar spines in asymptomatic individuals. The results also showed that the upper lumbar spine contributes more to the range of motion in flexion and extension than the lower lumbar spine in asymptomatic individuals without lumbar disc disease, as well as in patients with disc degeneration. It is well known that lower lumbar spine contributes more to the overall lumbar lordosis in the erect standing position [22]. However, during flexion/extension movements, the upper lumbar spine seems to contribute more to the overall range of movement. These findings cast a doubt on the existence of hypermobility of the upper lumbar spine following fusion of the lower lumbar segments. The finite element analysis of the functional spinal unit by Park et al. [23] showed increased intradiscal pressures in the discs adjacent to fused segments during flexion/extension and lateral bending, but intersegmental rotations decreased. Thus, hypermobility (instability) is likely to 'follow' and not 'precede' the degenerative changes in the adjacent disc. The hypermobility may be simply due to higher stress and instability in the disc adjacent to a fused segment 'following' significant degeneration of the stressed adjacent disc.

\section{Conflict of Interest}

No potential conflict of interest relevant to this article was reported.

\section{References}

1. Levin DA, Hale JJ, Bendo JA. Adjacent segment degeneration following spinal fusion for degenerative disc disease. Bull NYU Hosp Jt Dis 2007;65:29-36.

2. Kumar MN, Jacquot F, Hall H. Long-term follow-up of functional outcomes and radiographic changes at adjacent levels following lumbar spine fusion for degenerative disc disease. Eur Spine J 2001;10:309-13.

3. Anandjiwala J, Seo JY, Ha KY, Oh IS, Shin DC. Adjacent segment degeneration after instrumented posterolateral lumbar fusion: a prospective cohort study with a minimum five-year follow-up. Eur Spine J 2011;20:1951-60.

4. Etebar S, Cahill DW. Risk factors for adjacent-segment failure following lumbar fixation with rigid instrumentation for degenerative instability. J Neurosurg 1999;90(2 Suppl):163-9.

5. Lee CS, Hwang CJ, Lee SW, et al. Risk factors for adjacent segment disease after lumbar fusion. Eur Spine J 2009;18:1637-43.

6. Parkinson S, Campbell A, Dankaerts W, Burnett A, O'Sullivan P. Upper and lower lumbar segments 
move differently during sit-to-stand. Man Ther 2013; 18:390-4.

7. White AA III, Panjabi MM. Clinical biomechanics of the spine. 2nd ed. Philadelphia: Lippincott Williams \& Wilkins; 1990.

8. Morvan G, Mathieu P, Vuillemin V, et al. Standardized way for imaging of the sagittal spinal balance. Eur Spine J 2011;20 Suppl 5:602-8.

9. Pope MH, Hanley EN, Matteri RE, Wilder DG, Frymoyer JW. Measurement of intervertebral disc height. Spine (Phila Pa 1976) 1977;2:282-6.

10. Wilke HJ, Rohlmann F, Neidlinger-Wilke C, Werner K, Claes L, Kettler A. Validity and interobserver agreement of a new radiographic grading system for intervertebral disc degeneration. Part I: lumbar spine. Eur Spine J 2006;15:720-30.

11. Ahn DK, Park HS, Choi DJ, Kim KS, Yang SJ. Survival and prognostic analysis of adjacent segments after spinal fusion. Clin Orthop Surg 2010;2:140-7.

12. Kumar MN, Baklanov A, Chopin D. Correlation between sagittal plane changes and adjacent segment degeneration following lumbar spine fusion. Eur Spine J 2001;10:314-9.

13. Oda I, Cunningham BW, Buckley RA, et al. Does spinal kyphotic deformity influence the biomechanical characteristics of the adjacent motion segments? An in vivo animal model. Spine (Phila Pa 1976) 1999;24: 2139-46.

14. Akamaru T, Kawahara N, Tim Yoon S, et al. Adjacent segment motion after a simulated lumbar fusion in different sagittal alignments: a biomechanical analysis. Spine (Phila Pa 1976) 2003;28:1560-6.

15. Lee S, Ahn DK, Jeong KW, Kim HS, Seo YH, Park HS. Altered sagittal rotation after segmental fusion in degenerative lumbar disease: comparative study by level, length of fused segments. J Korean Soc Spine Surg 2004;11:231-7.

16. Chou WY, Hsu CJ, Chang WN, Wong CY. Adjacent segment degeneration after lumbar spinal posterolateral fusion with instrumentation in elderly patients. Arch Orthop Trauma Surg 2002;122:39-43.

17. Axelsson P, Johnsson R, Stromqvist B. Adjacent segment hypermobility after lumbar spine fusion: no association with progressive degeneration of the segment 5 years after surgery. Acta Orthop 2007;78:8349.

18. Kettler A, Rohlmann F, Ring C, Mack C, Wilke HJ. Do early stages of lumbar intervertebral disc degeneration really cause instability? Evaluation of an in vitro database. Eur Spine J 2011;20:578-84.

19. Mimura M, Panjabi MM, Oxland TR, Crisco JJ, Yamamoto I, Vasavada A. Disc degeneration affects the multidirectional flexibility of the lumbar spine. Spine (Phila Pa 1976) 1994;19:1371-80.

20. Burton AK. The ratio of upper lumbar to lower lumbar sagittal mobility related to age, sex, and low back trouble. Eng Med 1987;16:233-6.

21. Li G, Wang S, Passias P, Xia Q, Li G, Wood K. Segmental in vivo vertebral motion during functional human lumbar spine activities. Eur Spine J 2009;18: 1013-21.

22. Troyanovich SJ, Cailliet R, Janik TJ, Harrison DD, Harrison DE. Radiographic mensuration characteristics of the sagittal lumbar spine from a normal population with a method to synthesize prior studies of lordosis. J Spinal Disord 1997;10:380-6.

23. Park WM, Kim K, Kim YH. Effects of degenerated intervertebral discs on intersegmental rotations, intradiscal pressures, and facet joint forces of the whole lumbar spine. Comput Biol Med 2013;43:1234-40. 